\title{
Effect of partial reinforcement trial sequences on extinction performance'
}

JAMES E. SPIVEY AND DAVID T. HESS UNIVERSITY OF KENTUCKY

An investigation was conducted to examine the relative influence of $N-R, R-N$, and $R-R$ transitions on the extinction performance of albino rats following abbreviated training in a runway. The results were discussed in relation to the modified aftereffects hypothesis.

Within a partial reinforcement pattern, the four basic kinds of trial sequences (transitions) which may occur are $N-R, N-N, R-R$, and $R-N$. Recent research attests to the importance of considering these different types of transitions as the basic logical units to be employed in an analysis of the effects of partial reinforcement on the performance of albino rats in instrumental reward learning situations.

Spivey (1967) found that following abbreviated training in a runway extinction performance was an increasing function of number of $\mathrm{N}-\mathrm{R}$ transitions and was independent of reinforcement percentage. Spivey, Prada, \& Black (1967) have reported that with extended training $\mathrm{R}-\mathrm{N}$ transitions act to reduce the resistance to extinction of an operant response. Finally, Spivey, Hess, \& Aponte (1967) found that resistance to extinction for rats given abbreviated training in a runway was an increasing function of $R-R$ transitions. The results of each of these three studies were interpreted as supporting the modified aftereffects hypothesis (Capaldi, 1967).

The present investigation was concerned with comparing, within a single experiment, the relative effects of $N-R, R-N$, and $R-R$ transitions on extinction performance following abbreviated training.

Method

The Ss were 36 naive, 90-day-old, male albino rats of the Sprague-Dawley strain, supplied by the Holtzman Co. of Madison, Wisconsin. Twelve Ss were randomly assigned to each of three groups.

The apparatus was a wire-covered plywood runway, 75 in. long $\times 4$ in. wide $\times 9$ in. deep. The initial 60 in. midgray portion was separated from the 15 in. flatblack goalbox (GB) by an aluminum guillotine-type door which was used to prevent retracing. At the rear of the GB was a two-compartment aluminum food cup which could be moved perpendicular to the alley so that only one compartment, measuring $2 \times 4 \times 1-1 / 2$ in., was in the GB at a time. Running times over a 60 in. distance were computed by summing the alley and goal section times which were recorded on Standard Electric Timers connected to a 10 in. floor treadle and to two photocells located $48 \mathrm{in}$. and $60 \mathrm{in}$. beyond the treadle. When $S$ passed the last photobeam, located
$3 \mathrm{in.}$. in front of the food cup, the tight-fitting aluminum cup lid was silently and swiftly pulled through the rear of the GB by a small noiseless motor.

After three days of ad lib food the $23 \mathrm{~h}$ food deprivation schedule was initiated (Day 1 of training). On Days 10-13 of training each S was individually handled in the experimental room for $15 \mathrm{~min}$ on a 36 in. square aluminum pan with wet mash continuously available at the approximate time $S$ was to be run. On Day 14 each $S$ was given two 2 min $R$ placements in the GB, each of which was followed by a 1 min confinement in the 12 in. square $\times 24$ in. deep unpainted wooden intertrial interval (ITI) box. On Day 15 four $1 \mathrm{~min}$ $R$ placements were given, and the ITI was $30 \mathrm{sec}$. On Days 16 and 17 each $S$ was given $1 \mathrm{R}$ running trial in the alley; both GB and ITI box confinement durations were $30 \mathrm{sec}$. Beginning on Day 16 , if $S$ did not complete a section of the alley within $60 \mathrm{sec} S$ was gently forced into the GB, and $60 \mathrm{sec}$ was recorded for each uncompleted section.

On each of the three days of acquisition, Days 18-20, four running trials were given according to one of the following patterns, NNRR (Group N-R), RRNN (Group $\mathbf{R}-\mathrm{N}$ ), or RRRR (Group $\mathbf{R}-\mathrm{R}$ ). On $\mathrm{R}$ trials $\mathrm{S}$ was confined to the GB for $15 \mathrm{sec}$ with the food compartment containing wet mash; on $\mathrm{N}$ trials $\mathrm{S}$ was confined for $15 \mathrm{sec}$ with the empty food compartment while wet mash was present, though not visible, in the adjoining compartment. The ITI was 15 sec.

On Day 21 an initial $R$ trial was given and was followed by $13 \mathrm{~N}$ trials. The extinction procedures were identical to those of acquisition, including the presence of wet mash in the adjoining compartment. If an $S$ failed to complete the alley section within $60 \mathrm{sec}$ on three successive trials, that $\mathrm{S}$ was considered "extinguished," and $60 \mathrm{sec}$ was assigned for both the alley and goal sections for each of the remaining trials.

Resulis

The group mean log running times in extinction are presented in Fig. 1. All analyses were performed on the logarithms of the individual S's running times. Analyses of variance indicated that the groups did not significantly differ on the initial trial of acquisition $(F<1)$, or on Trial $R$ of extinction $(F=2.61, d f=2 / 33$, $.05<\mathrm{p}<.10)$. A between-groups analysis of variance applied to $\mathrm{N}$ Trials 2-13 indicated that the groups differed greatly in average extinction running speed ( $F=10.95$, df $=2 / 33, p<.001)$. Subsequently, Duncan's multiple range test (Edwards, 1960) revealed that Group $N-R$ ran faster than either Group $R-N$ or Group $R-R$, 


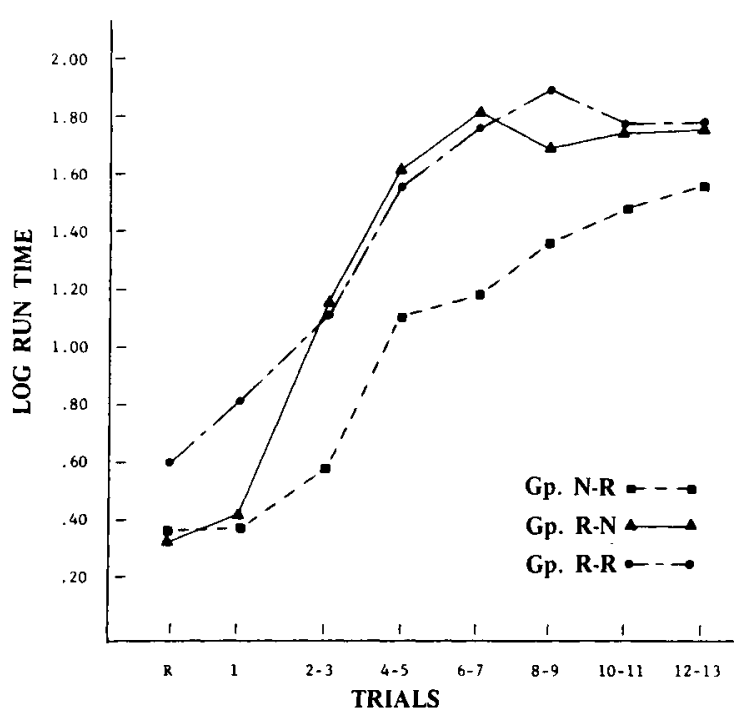

Fig. 1. Group mean log running time in extinction. Trial $\mathbf{R}$ was reinforced and Trials 1.13 were nonreinforced.

$p<.001$ in each case, while for the comparison of Group R-N with Group R-R, .05< p $<.10$.

A repeated measures analysis of variance, used to assess the Groups by Trials interaction over $\mathrm{N}$ Trials 1-13 of extinction, indicated that $\mathrm{p}<.01, \quad(\mathrm{~F}=2.04$, $\mathrm{df}=24 / 396$ ). Similar analyses were applied to the different group pairings. For Groups $\mathrm{N}-\mathrm{R}$ and $\mathrm{R}-\mathrm{N}$, $p<.001(F=3.02, d f=12 / 264)$; for Groups $N-R$ and $R-R$, $.05<p<.10(F=1.67, d f=12 / 264) ;$ for Groups $R-N$ and $R-R, p>.10(F=1.35, d f=12 / 264)$.

\section{Discussion}

The results indicate that the dominant sequential variable influencing extinction performance was $N-R$ transitions. The findings relative to Groups $R-N$ and $\mathrm{R}-\mathrm{R}$ are less clear-cut. It was anticipated that Group $\mathrm{R}-\mathrm{R}$ might be more resistant to extinction than Group $\mathrm{R}-\mathrm{N}$ since the former group had more R-R transitions and no R-N transitions (Spivey, Hess, \& Aponte, 1967; Spivey, Prada, \& Black, 1967).

It is possible that $\mathrm{R}-\mathrm{N}$ transitions in the acquisition reinforcement schedule do not act to decrease resistance to extinction following abbreviated training. There is little available evidence which bears directly on this point since $\mathrm{R}-\mathrm{N}$ transitions have not been given much attention in reinforcement pattern studies. However, those investigations which have employed a single alternation (SA) pattern of reinforcement appear to be relevant (e.g., Bloom \& Capaldi, 1961; Capaldi \& Lynch, 1966; Capaldi \& Spivey, 1964b). These studies have found that rats, after running equally fast on trials following reinforcement (TFR) and trials following nonreinforcement (TFN), come to exhibit appropriate alternation of response speeds by slowing down on $T R F s$. Thus, proper alternation behavior seems to depend mainly on the accretion of inhibition to the aftereffect of reinforcement $\left(S^{R}\right)$. Further, this inhibition resulting from the $\mathrm{R}-\mathrm{N}$ transitions in the SA schedule appears to have an effect only late in training. It would not be surprising, therefore, to find that $\mathrm{R}-\mathrm{N}$ transitions do not appreciably affect performance with abbreviated training.

Even if $\mathrm{R}-\mathrm{N}$ transitions had no effect in the present experiment, Group R-R still might have been more resistant to extinction than Group $R-N$ since the former group received the greater number of $\mathrm{R}-\mathrm{R}$ transitions (Spivey, Hess, \& Aponte, 1967). This expectation would be based on the assumption that with highly abbreviated training Group $\mathrm{R}-\mathrm{N}$ would not profit from the $\mathrm{N}-\mathrm{R}$ transitions occurring across a $24-h$ ITI. As this last factor may indeed have played a part, it would be most informative to replicate the present experiment with the added use of a procedure (e.g., intertrial reinforcement) which would prevent the conditioning of the aftereffect of nonreinforcement $\left(\mathrm{S}^{\mathrm{N}}\right)$ across days (see Capaldi \& Spivey, 1964a).

\section{References}

BLOOM, J. M., \& CAPALDI, E. J. The behavior of rats in relation to complex patterns of partial reinforcernent. J. comp. physiol. Psychol., 1961, 54, 261-265.

CAPALDI, E. J. A sequential hypothesis of instrumental learning. In K. W. Spence and J. T. Spence (Eds.), The psychology of learning and motivation. Vol. 1. New York: Academic Press, 1967.

CAPALDI, E. J., \& LYNCH, A. D. Patterning at 24-hr ITI: Resolution of a discrepancy more apparent than real. Psychon. Sci., 1966, $6,229-230$.

CAPALDI, E. J., \& SPIVEY, J. E. Intertrial reinforcement and aftereffects at 24-hr intervals. Psychon. Sci., 1964a, 1, 181-182.

CAPALDI, E. J., \& SPIVEY, J. E. Stimulus consequences of reinforcement and nonreinforcement: Stimulus traces or memory. Psychon. Sci., 1964b, 1, 403-404.

EDWARDS, A. L. Experimental design in psychological research. (Rev. Ed.) New York: Rinehart \& Co., Inc., 1960.

SPIVEY, J. E. Resistance to extinction as a function of number of N-R transitions and percentage of reinforcement. J. exp. Psychol., $1967,75,43-48$.

SPIVEY, J. E., HESS, D. T., \& APONTE, J. F. Extinction performance as a function of R-R transitions with abbreviated training. Psychon. Sci., 1967, 9, 147-148.

SPIVEY, J. E., PRADA, J., \& BLACK, D. Extinction performance following different levels of training under a single alternation pattern of reinforcement. Paper read at Southeast. Psychol. Assoc. Conv., Atlanta, 1967.

Note

1. This research was supported by NIMH Grant MH 13371-01, by research grants from the University of Kentucky Research Committee, and by a University of Kentucky Summer Faculty Research Fellowship, each to the first author. 